\title{
MEDICAL PRACTICE IN A PUBLIC SCHOOL
}

\author{
J. P. SPARKS, M.D., M.R.C.P. \\ Medical Officer, Rugby School
}

Public School medicine as a specialized branch of medical practice has a history of little more than a century. The appointment of a resident medical officer to Marlborough College in 1848 marked the start of a trend that was to be followed in many of the bigger schools. Until this time medical practice in schools was somewhat haphazard, and very little had been done in the way of preventive medicine. The records of medical practice in schools prior to this date are scanty and such references as exist are mainly to outbreaks of infectious diseases-plague being preeminent up to the i8th century, when smallpox and scarlet fever assumed the principal roles.

In the Igth century the Lancet campaigned vigorously against the poor living conditions, lamentable sanitation, inadequate diet and dubious medical attention available in the schools. A Lancet commission in 1875 made a number of strong recommendations-that a medical officer should be attached to each school, and that he should control directly all sanitary matters. The commission favoured periodical examination of the pupils to eliminate the importation and spread of contagious and infectious diseases.

In 1884 the Medical Officers of Schools Association was founded, and in 1885 it published a Code of Rules on school health and communicable diseases. This publication promoted a uniformity of practice in the schools and has since been a valuable guide to school medical officers. The 12th edition, published in 1954, was expanded into a handbook of 78 pages.

The Medical Officers of Schools Association has two simply expressed aims: (I) mutual assistance by the members in promoting school hygiene and (2) the holding of meetings for the consideration of all subjects connected with the special work of medical officers of schools. Membership is open to medical officers of schools and of children's hospitals and to medical practitioners especially engaged in the study of ailments of the young. Members of the scholastic profession are eligible for associate membership.

Today the Association has about 250 members.
It meets several times a year in London and occasionally elsewhere. Papers are given either by outside speakers or by members based on their personal experiences. The Council discusses a great variety of problems connected with health in schools and is the one body that can express an authoritative opinion on medical practice in the public schools.

\section{Rugby School}

I have been unable to find anything about the early days of medicine in the community. The school was founded in $15^{6} 7$ by Lawrence Sheriff and moved to its present site on the southern outskirts of the town in 1698 . The majority of the buildings are mid- or late Victorian and the school can claim no architectural distinction. The first sanatorium was built in about $185^{\circ}$. It is said that the design was based on that of a Norwegian fever hospital and that the building was intended to be a wooden construction to be burned down every seven years. The then headmaster would not hear of this, so the sanatorium was brick built and remained in use as a sanatorium until 1934. The building still provides classrooms for the school and living accommodation for a member of the staff.

In 1868 a Dr. Farquharson was appointed as medical officer. He made his mark quickly by reducing a dislocated shoulder on the field of play his first day in the school. In an entertaining autobiography ('In and Out of Parliament') he confesses that he was not so fortunate a little later when the headmaster, Dr. Frederick Temple (later Archbishop of Canterbury and father of William Temple) sustained a similar injury. After three years, following a change in the headmastership, Farquharson left the school for practice in London and became a member of Parliament and a P.C. He was succeeded by Dr. Clement Dukes, one of the great figures of public school medicine. He remained as medical officer from 1871 to 1908 and returned in the capacity of locum tenens during the Great War. His output of published work was prodigious. Dukes was the first person to 
recognize the insignificance of adolescent albuminuria-in his opinion 'a transient functional perturbation of the vasomotor system '-and courageously removed the restrictions which had previously curtailed the activities of many adolescents. Among his many published works, 'Health at School' was the best known. It ran to four editions and covers every aspect of school life. In it Dukes describes 'The Fourth Disease' (or Filatov-Dukes disease), making a clear distinction between it and scarlet fever.

Dr. A. I. Simey succeeded Dukes in 1908 and remained till 1931, apart from service in the Great War. He campaigned strongly for a later evening meal for the boys and was instrumental in abolishing quarantine for most infectious diseases, substituting instead a system of surveillance. Boys exposed to infectious diseases in the holidays were allowed to return to school, provided they had been kept away from the source of infection after the original exposure.

Dr. R. E. Smith was medical officer from 193I-50. He had faith in Simey's system of surveillance, establishing it on a firm basis in the school and advocating its adoption in other schools. He had a large say in the design of the new sanatorium opened in 1934 and has published a wide variety of papers. He gave the Milroy Lectures of 1940 to the Royal College of Physicians on 'Acute Infectious Diseases at School'. He wrote a valuable paper with Dr. John Lambert, of Wellington College, on 'Torsion of the Testicle and of the Hydatid of Morgagni' and delivered a Hunterian Lecture to the Royal College of Surgeons of England in 1941 on "The Undescended Testicle'. In $195^{\circ}$ Dr. Smith left the school to continue work as a consultant physician to hospitals in Coventry and Rugby and was appointed consultant physician to the school.

\section{The Functions of the Medical Officer to a Public School}

The medical officer should be appointed by, be responsible to and have direct access to the governing body of the school. The medical officer functions in several capacities; in his day-to-day work he is the doctor to the boys and to those members of the staff and their families who so wish. He must take responsibility for the hygienic state of all the school buildings, advising the governing body of necessary improvements. He must work in close association with the headmaster, keeping him informed of trends in the incidence of disease; he should be in a position to advise on the boys' diet, the amount of exercise and preventive measures. Above all, the medical officer should act in an advisory and never in an executive capacity. He should know all the mem- bers of the staff, but should not be too closely involved in ties of friendship with individual members. He should strive to know the boys in health, in their everyday activities, as well as in illness or injury. A medical officer can only give a full service to the school when he is familiar with all the personalities and the activities of the community as a whole.

The medical officer whose main professional concern is his position of medical officer to a school seems to me to be better placed to give a good service than his more numerous part-time colleagues. On the other hand, only the larger schools can afford the luxury of a near full-time medical officer. Some schools have a panel of several medical officers, each looking after a part of the school. It must be difficult in these circumstances to visualize illnesses affecting sections of the school as entities, difficult to obtain uniformity of practice, and difficult to practise preventive medicine.

\section{The Medical Arrangements at Rugby}

Since Farquharson's appointment in 1868 the school has always had the major part of the medical officer's services and enjoys absolute priority in claim to his services. This enables the medical officer to do some work-private or consulting practice-to a limited extent outside the community, a factor of great importance in preventing him settling in a rut, and also in helping him to maintain an up-to-date and wide appreciation of medicine when, as is inevitable at times, his school commitments are small.

The school medical services are centralized in the sanatorium. The present building was opened in 1934. It was designed by Fairweather, who had previously designed the Epsom College sanatorium, and the then headmaster, Dr. W. W. Vaughan, and Dr. R. E. Smith had much influence on the ultimate design. There are 59 beds -23 in single rooms, three four-bedded wards and two eight-bedded wards, each with a four-bedded annexe. Apart from the isolation obtainable in single rooms, the sanatorium is so constructed that various blocks in it can be isolated as selfcontained independently functioning units. The surgery is well equipped, surgeries being held twice daily throughout the term. The operating theatre is admirable and, unlike the practice in many schools, it is used regularly-on an average 12 operations under anaesthesia are performed each term. Not only are operations performed on the boys, but also on members of the staff and their families, who are entitled to admission to the sanatorium when necessary.

Since the inception of the National Health Service in 1948 the boys have been placed on the 
medical officer's list (under the Warwickshire Executive Council), holiday treatment elsewhere being obtained on the basis of temporary residence. Operations and consultations in the sanatorium are obtained privately, most parents being insured under one of the hospital insurance schemes. About to per cent. of parents ask for National Health Service treatment only for their children; in such cases transfer to a hospital would be necessary were an operation required. The advent of the Health Service has been of assistance to the medical officer, eliminating a considerable amount of book-keeping and making more readily available certain ancillary facilities, e.g. radiological and laboratory services. One major difficulty in maintaining a hospital-type service, although he is technically a general practitioner, is his inability to prescribe in bulk on E.C.Ios many of the more useful drugs. All Schedule 4 drugs must be prescribed individually and, as Schedule 4 includes all the specific drugs of choice, one frequently has to write out about 700 individual prescriptions, usually at a time when one is busy.

The medical officer's secretary maintains two parallel sets of records - the N.H.S. records, which are withdrawn when the boy leaves, and the private school records, which remain. The school records are kept in a large filing cabinet, a separate record envelope being allocated to each boy. This envelope records significant information on the front and contains inside all the correspondence, medical forms, X-ray reports, temperature charts, etc., affecting the boy during his school career.

Four trained nurses staff the sanatorium. Nursing duties are shared more or less equally, the duties being allocated by a sister in charge, who is responsible for organizing the nursing services. A cook-housekeeper, responsible to the sister in charge, deals with the domestic duties.

Surgeries are held twice daily throughout term, boys going first to their house matron, who then refers them to the sanatorium. Emergencies are admitted at any time, the routine admissions tending to arrive in relation to the surgeries. Casualty work varies with the term, rugger providing far the greatest number of injuries, with general accidents a bad second.

After morning surgery the medical officer and sister in charge go round the in-patients. In the evening the medical officer visits any in-patients who require a further visit. A daily report on each patient is sent to the headmaster, who sends the reports on to the housemaster, who then communicates with the boy's parents. This system of communication saves the medical officer from much correspondence, but occasionally causes difficulties, usually due either to the non-transmission of available information or to its misinterpretation.
If the medical officer writes directly to a parent, he sends a copy to the housemaster concerned for information.

The II boarding houses have sick rooms, whose functions are strictly limited-few house matrons have nursing qualifications-so only minor illness is nursed in the boarding house, and then only for 24 hours or less. In epidemic times boys must at times be nursed in the houses, often in considerable numbers, putting a considerable strain on the house staffs.

From the start of term until the discharge of the last in-patient at the end of term the sanatorium maintains a continuous service. Many people imagine that a school doctor has a quiet, easy life, but one can safely say that 13 weeks' continuous duty imposes a considerable strain on the doctor, who, in common with the teaching staff, is tired by the end of a normal term. A violent epidemic, with some serious cases of illness, when coupled with the normal routine, stretches the medical officer to the utmost. One aspect of school medicine, which I had never considered until I came to Rugby is that the medical officer is not the doctor of the parents' choice-he is the doctor at the school of the parents' choice. The home doctor is the boy's 'proper' doctor, a fact well recognized by the boys themselves, who, at Rugby, traditionally refer to their medical officer as "The Quack'. For this reason the medical officer must at all times endeavour to maintain the highest professional standards, not hesitating to make use of second opinions, and using ancillary facilities to the utmost. The parent or home doctor should inform the school doctor if a boy returns to school to continue treatment initiated in the holidays.

All boys are medically examined as early as possible in their first term. At the examination the medical officer has available to him a comprehensive medical form completed by the parent. The commonest defects noted at this examination are errors of refraction, defects of colour vision and orthopaedic defects. The medical officer reports on each boy's state of health, together with any advice he may offer on games or general management. This report goes to the boy's housemaster, who communicates with the parent.

There are no further routine medical examinations. I am sceptical of the value of periodical examinations, and it is always an easy matter for a parent or housemaster to ask for an examination when health is suspect.

The medical officer makes an annual inspection of all the school buildings, submitting a report to the governing body. Other inspections are made at irregular intervals to make sure that the day-today maintenance is being adequately covered. 


\section{The Boys}

As this is an article on public school medicine, it is essential to have some picture of the clinical material-the boys themselves. Entrance to Rugby School is by examination and the competition is such that the average intelligence is high. The intelligence quotient has not gained many adherents among the teaching staff and one is well aware of the limitations of such tests, but, using the Cattell tests (Scales II and III), I have examined several hundred boys. The average I.Q. of members of the lowest group of forms in the school is 137 , while that of the members of two of the top forms is 172 . These are remarkable figures, and one should remember that the teaching is geared to boys of a high academic level.

Boys come from all over the world; many are sons of old Rugbeians. The parents' occupations cover an enormous range, members of the medical profession constituting the biggest single groupabout one boy in six is the son of a doctor.

Adolescence is a term which gives rise to rather vague ideas in most people's heads. If asked, one would probably say that adolescence in boys began at 12 to 13 and ended at 16 to 17 . Some figures, which Dr. T. A. A. Hunter, medical officer to Marlborough College, recently presented in a paper to the Medical Officers of Schools Association, make one think about the problem of adolescence in a public school.

Hunter's figures, based on the periodic examination of over 800 boys in the last five years, are as follows:

$\begin{array}{cccc}\text { Stage of Development } & \text { at } & \text { Age } 13 \frac{1}{2} \text { Years } \\ \text { Prepubertal } & \ldots & \ldots & 27 \% \\ \text { Pubertal } & \ldots & . & 48 \% \\ \text { Postpubertal } & \ldots & . . & 25 \%\end{array}$

Most school activities, and games in particular, are based on the assumption that boys should stick to their own age groups. These figures show that on entry to a public school a quarter of the boys are children, a half are adolescent and a further quarter are adult. When one thinks of the enormous variations, physical, physiological and psychological, that such figures imply, one wonders whether schools are sufficiently conscious of the differences in individual boys. Further figures of Hunter's give an average for the duration of puberty of two years, three months, with variations between three years, one month and one year, six months. He gives the latest observed onset of puberty as being 16 years, II months, and estimates the earliest onset of puberty to have been ro years, six months.

The period of greatest growth for the average boy is from 14 to 15 years, with the years before and after not far behind. Such a period of rapid growth and development makes great demands on the boy and it is inevitable that work should suffer to some extent during this period.

When the pressure on passing examinations and obtaining university entrance is as great as it is at present, it is not always easy to keep these facts in perspective. Many boys can take external pressure in their stride, but others need help at this time, and some indeed may well work themselves out by attempting too much.

The average boy of today is bigger and heavier than his predecessors-each decade it is necessary to review one's standards as the earlier ones become obsolete. Table I gives four sets of figures: Roberts's figures of 1874 referring to children of the professional classes, Friend's figures for 1905-17 and 1930-33 from Christ's Hospital, and my figures from Rugby for 1953-58. Heights are measured in socks, weights in shirts and trousers.

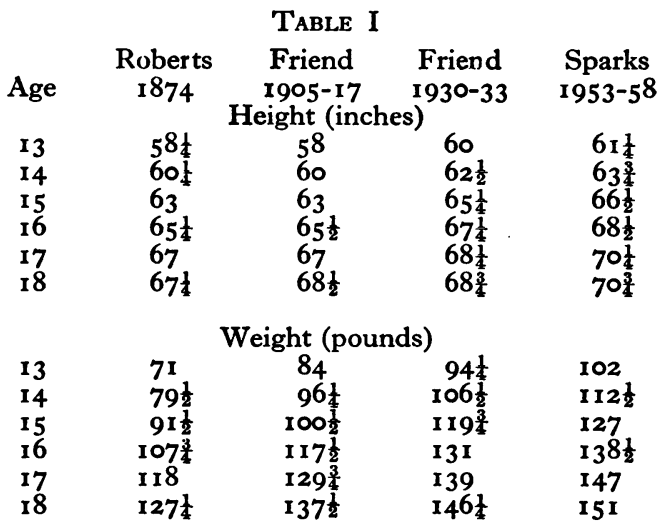

Adolescence is a period of stress and unrest, of changing outlooks and interests. Shyness is often prominent and it may take months or even years to break down the reserve of some boys. The development of the sexual organs is accompanied by a natural curiosity, giving rise to behaviour disorders at times. Help is needed by many boys at this time, but there is no unanimity on the ideal way of handling these problems. I find myself confused and no longer have definite views. During the past decade instruction was originally given to the boys in groups by a visiting doctor; later the medical officer talked to small groups of boys, and now the housemasters talk to their boys individually. There are good and bad points in each method-I only wish that all parents were able to discuss the problems freely with their children. The medical officer can play an important role in other behaviour disorders as long as he acts in an advisory capacity. He should be a person, as should the chaplain, to whom boys can go freely when they are in doubt and confused, 
and it is a measure of his success if he can obtain the confidence of his patients.

A description of some of the common and more interesting illnesses and injuries seen in school practice contributes to the picture of public school medicine. As in ordinary general practice, the variety is legion and one is constantly meeting new problems and unusual conditions. From year to year one notices a changing pattern of disease, bringing new problems to one's attention.

\section{Infectious Diseases}

Simey's policy of surveillance has been continued and progressively expanded. The proviso is made that the boy should be kept away from the source of infection after the original contact. On return to school the house matron takes the boy's morning and evening temperature during the incubation period, sending him to the sanatorium should he develop a pyrexia or feel unwell in any way. In his Milroy Lectures of 1940 Smith gives his experience of the years $1931-39$. During this period there were six outbreaks of measles, five of mumps, nine of rubella, nine of scarlet fever, two of whooping cough, I I of chickenpox and one of diphtheria. Not one of the originators was aware of having been in contact with the disease he contracted. On the other hand, 128 boys who had been in known contact with cases of infectious disease returned to school in this period, and only two of them developed the disease to which they had been exposed-a case of mumps and one of whooping cough. Neither gave rise to an epidemic. Had full quarantine been enforced in the 128 cases 2,5 I I days of education (approximately ro education years) would have been lost.

Recent experience confirms the soundness of surveillance. During the last six years there have been three outbreaks of measles, five of mumps, four of chickenpox, six of rubella, one of whooping cough, two of scarlet fever and one of poliomyelitis. In only one case (mumps) did the originator know that he had been in contact with a case. Seventy-six boys exposed to various diseases have returned to school in this period without developing the diseases.

\section{TABle II}

$\begin{array}{lccr}\text { Measles .. } & \ldots & \ldots & \mathbf{8 9 \%} \\ \text { Chickenpox } & . & . . & 86 \% \\ \text { Whooping cough } & \ldots & 63 \% \\ \text { Mumps .. } & \ldots & \ldots & 58 \% \\ \text { Rubella } & \ldots & \ldots & \mathbf{4 2} \% \\ \text { Scarlet fever } & \ldots & \ldots & \mathbf{6 \%} \\ \text { Poliomyelitis } & \ldots & \ldots & \mathbf{1} \%\end{array}$

Table II shows the percentage of the current school population who have had specific infectious diseases prior to entry to Rugby.
Double attacks (i.e. a fresh attack in a boy who is considered to have already had the disease) have been:

$\begin{array}{lllll}\text { Measles } & \ldots & \ldots & \ldots & 6 \\ \text { Rubella } & \ldots & \ldots & \ldots & 6 \\ \text { Mumps } & . & \ldots & \ldots & 3\end{array}$

One case of herpes zoster was recorded in a boy who had had chickenpox.

The total number of cases diagnosed in the school in the last six years have been:

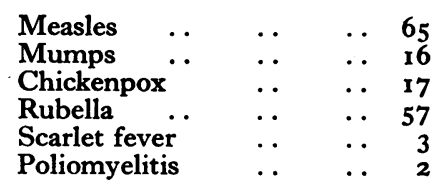

There is little to note in the clinical manifestation of the various diseases. Two of the mumps cases developed orchitis and one pancreatitis (no sequelae). Two of the rubella cases developed corneal ulcers. One of the poliomyelitis cases developed paralysis and was ultimately left with some weakness of the right serratus anterior.

\section{Influenza}

This disease, above all others, dislocates life in the school. A violent outbreak rapidly fills the sanatorium, overflowing into the boarding houses and putting a strain on all the school staff.

Outbreaks of influenza in the school in the past ro years are shown in Table III.

TABLE III

\begin{tabular}{l|l|c|c}
\hline \multicolumn{1}{c|}{ Date } & \multicolumn{1}{c|}{ Variety } & \multicolumn{1}{c}{$\begin{array}{c}\text { No. of } \\
\text { cases }\end{array}$} & $\begin{array}{c}\text { Attack } \\
\text { rate, \% }\end{array}$ \\
\cline { 1 - 2 } January, 195 I & A Prime & 233 & 38 \\
January, 1953 & A Prime & 67 & 1 I \\
June, 1954 & B & 309 & 50 \\
January, 1955 & B & 54 & 9 \\
January, 1956 & A Prime & 90 & 14 \\
September, 1957 & A-Asiaticus & 505 & 79 \\
January, 1959 & A and B & 432 & 66 \\
\hline
\end{tabular}

Prior to January I95I the last outbreak of influenza in the school had been in January 1947 (type not known). The duration of immunity conferred by an attack is not known with any certainty. From consideration of the figures in Table III, one can conclude that immunity is type specific, that a new virus variant will find the community virtually unprotected, and that an individual attack will only supply a partial immunity-subsequent attacks will raise the level of immunity, several attacks conferring a high level of immunity, lasting for some years.

The outbreak of Virus B influenza in June 1954 was of interest. In December 1953 volunteers 
in the school were vaccinated at random with Virus A or Virus B influenza vaccine provided by the Influenza Trials Committee of the Medical Research Council. The outbreak of influenza B occurred six months later, and at that time onethird of the school had received Virus $A$ vaccine six months previously, one-third had received Virus B vaccine, and one-third had had neither. The attack rate was similar in the unprotected and the Virus A groups- 56 per cent.-but in the Virus B group was 40 per cent. This difference was considered significant. Of the 54 cases of Virus B influenza that occurred in January 1955, there were 30 cases in the 513 boys who had been in the school during the outbreak of Virus B influenza in June 1954, an attack rate of 6 per cent.; whereas there were 24 cases in the IOI boys new to the school, an attack rate of 24 per cent.

The outbreak of September 1957 was easily the most explosive of the series. The daily case incidence of this epidemic is shown in Table IV.

Table IV

Daily Case Incidence of Influenza, Autumn, 1957 Day $\begin{array}{r}1-1 \\ 2-4 \\ 3-8 \\ 4-11 \\ 5-19 \\ 6-43 \\ 7-78 \\ 8-67 \\ 9-70 \\ 10-62 \\ 11-43\end{array}$

Day $12-39$

$13-13$

$14-10$

15- 9

$16-1$

$17-2$

$18-2$

$19-3$

$20-1$

$2 \mathrm{I}-2$

Unrestricted admission to the sanatorium was stopped in the evening of the fifth day. During the next seven days 402 fresh cases occurred, the majority being nursed in the boarding houses. Each day the medical officer estimated the number of available beds in the sanatorium, made a round of the boarding houses and admitted to the sanatorium the more serious cases. The handling of the epidemic was complicated by the illness of many members of the staff and their families, but improvisation and co-operation from evervone enabled the community to weather the outbreak. One boy developed a fulminating pneumonia, surviving after being desperately ill for several weeks. Unfortunately he developed extensive bronchiectasis. There were four other cases of pneumonia - the incidence of this complication in influenza epidemics is just under I per cent. Two boys developed appendicitis during the course of their illness, one causing great diagnostic difficulty. One boy developed a paralytic brachial neuralgia at the end of a mild attack.

An outbreak of influenza in the community lowers the resistance of the individual-an out- break in January has always been succeeded by an epidemic of pharyngitis which has persisted throughout the term. Post-influenzal depression does not occur in the adolescent, but many weeks elapse before the boys can be considered really fit - the weight loss in an attack of uncomplicated influenza in the adolescent is of the order of half a stone or more.

\section{Tuberculosis}

Two miniature radiographic surveys in the last decade disclosed no cases of active tuberculosis. Only one case of tuberculosis has been seen in this time- a case of erythema nodosum in a boy of 17 , in whom radiological evidence of a primary complex was disclosed three months later.

Mantoux testing (using a dose of ro T.U.) of new boys has been carried out for five years. Positive readings were obtained initially in 26 per cent., but in the last 12 months positive readings, excluding the small number of boys who have received $B C G$, have been less than 15 per cent. BCG vaccination has not been routinely advised, but has been given individually at the request of parents.

\section{Poliomyelitis}

Over 99 per cent. of the school population has been protected with three doses of Salk-type vaccine. This measure removes one of the school medical officer's greatest worries. The occurrence of poliomyelitis in the community causes natural anxiety to parents and considerably restricts life in the school. In 1955 two cases of poliomyelitis were diagnosed soon after the start of the autumn term. Both cases were in the same boarding house. All competitive games were stopped for three weeks and the amount of strenuous exercise was strictly limited. The members of the house in which the cases occurred were semi-isolated. No further cases developed. The two patients were nursed in the school sanatorium.

\section{Upper Respiratory Infections}

The common cold reaches a peak incidence in the third week of term, declining rapidly to rise again in the last fortnight. Epidemic pharyngitis is a frequent visitor. I feel that the outbreaks are viral in origin, possibly due to several unrelated viruses. In any given epidemic pathogenic bacteria are isolated in only a minority of the cases, and their distribution appears to be haphazard. From 1950-53 haemolytic streptococci were isolated in all the epidemics of sore throat, from ro to 15 per cent. of throat swabs being positive. Group A were always a minority and in each outbreak there were several different types. For the last six years the 
laemolytic streptococcus has been isolated seldom, the principal pathogen at present being a penicillininsensitive staphylococcus pyogenes.

Small outbreaks of adeno-virus and Coxsackie infection are occurring with increasing frequency, and I do not think that this is solely due to increasing familiarity with these diseases. For each virus infection that one can diagnose there are many others the nature of which is unsuspected by the medical officer. All the cases of pneumonia in the school in the past decade have been viral in origin, or have been inter-current complications of virus illnesses.

Otitis media is the commonest complication of upper respiratory infection. Such cases are seen within a short period of the onset and respond to antibiotics. No case of mastoiditis has been seen.

Sinusitis is common, usually responding to simple therapy, although antibiotics are occasionally used.

Ten years ago 70 per cent. of the boys had had their tonsils removed before entry. The most recent figure is 55 per cent. There is no difference in the incidence of upper respiratory infection in the two groups and tonsillectomy has been advised on only three occasions in Io years.

\section{Other Medical Conditions}

I think that many boys are accepted for public schools nowadays who would not have been considered even 30 years ago: spastics, diabetics, epileptics and cardiac invalids (congenital and rheumatic) have all been accepted and the majority have had successful school careers, limitation of exercise alone differentiating their careers from those of healthy boys. Nearly ro per cent. of the boys give a history of asthma, but few of them have trouble while at school. Enuresis occurs in less than I per cent. and is treated on sympathetic lines-the majority clear up during their first year in the school. Migraine commonly begins in adolescence, prophylactic treatment being reasonably successful in the worst cases. Hay fever and allergic rhinorrhoea are extremely common and have considerable nuisance value.

Acne is a troublesome adolescent complaint and many boys are sensitive about their appearance. Treatment is usually on the lines of dietary restrictions, the use of detergent solutions and actinotherapy. Some pustular cases are very resistant. I am always opposed to hormone treatment in adolescent acne. More recently the use of broad-spectrum antibiotics has achieved popularity. This is potentially dangerous and I dislike having to give prolonged courses. Two years ago I had one boy with a most disfiguring acne, treated by a consultant dermatologist with a lengthy course of oxytetracycline. After six months of this treatment the boy developed acute appendicitis, complicated by pelvic and retrocaecal abscesses, the organisms being insensitive to available antibiotics.

Minor sepsis-furunculosis, impetigo, whitlows -is seen frequently. I have no doubt that a relative excess of dietary carbohydrate is a contributory factor, as is the presence of carriers of Staph. pyogenes in the community.

\section{Fungus Infection}

Ten years ago the incidence of tinea pedis was over 70 per cent. A vigorous attack was made on the problem, directed both at the patient and his environment. The incidence has been reduced to ro per cent., most of the cases being mild. A high proportion of boys show evidence of this infection on entry to the school.

Tinea cruris tends to occur in small epidemics in individual houses. I am sure that bath towels play a large part in the spread of infection.

\section{Surgical Cases}

Acute appendicitis is easily the commonest surgical condition seen: 8 per cent. have had appendicectomy prior to entry, while another 5 per cent. have operations at school. I am firmly of the opinion that operation should take place if appendicitis is diagnosed. Signs in particular are often scanty, but a history of persistent pain in the right iliac fossa associated with tenderness is sufficient indication for operation. Frequently the patients are apyrexial with a steady pulse, and true abdominal rigidity is often absent in the early stages. Meckel's diverticulum has been found twice in the last 60 cases. One diagnostic rarity was noted last year-a boy of 14 presented with the signs and symptoms of acute obstructive appendicitis and was found at operation to have Crohn's disease with a normal appendix.

The operations are performed in the sanatorium theatre and three weeks after operation the boys are back in school, the majority returning to full games a week later.

\section{Torsion of the Testicle}

This occurs uncommonly, but constitutes a real emergency. A school medical officer is in the fortunate position of seeing these cases soon after the onset. Smith advocates manual reduction in the first instance and I endorse his views completely. As soon as the diagnosis is established morphia, $\frac{1}{4}$ grain, is administered. Three-quarters of an hour later manual reduction is attempted. I have dealt with four cases in the last ro years. In each case the right testicle was affected. Rotation in an anti-clockwise direction has brought 
speedy relief to the patient. The minimal rotation required was $180^{\circ}$ and the maximum was three complete rotations through $360^{\circ}$. Orchidopexy is undertaken within a few days.

Should manual reduction be unsuccessful, or if a satisfactory reduction seems uncertain, surgical exploration is imperative. I have not as yet encountered torsion in an undescended testicle.

\section{Games Injuries}

Rugger is directly or indirectly responsible for about 600 injuries a year. Many injuries occur in the early stages of the term during training-e.g. sprained ankle and pulled muscles - while others are due to insufficient training. Strains of the Tendo Achillis are very common, as is Schlatter's syndrome. During the present season the grounds were too hard at the beginning of the autumn term and, as a result, training was more prolonged than customary. In common with many other schools, we noted a marked decrease in the number of fractures and, more particularly, in the absence of cases of serious injuries to the lower limbs. I hope that the lesson will be assimilated. Injuries to the knee-joint are seen possibly more often in soccer than in rugger, but damage to the menisci and to the knee ligaments are frequent. In six years there have been 278 fractures in the school, and of these 153 , or rather more than half, were sustained at rugger. Dislocations at rugger chiefly affect the shoulder joint and finger joints; other dislocations are uncommon. Rupture of the spleen has been seen once in ro years and, in the same period, three cases of rupture of the kidney have occurred. Concussion cases number about 30 a season.
Other games produce many fewer injuries in total quantity, but in proportion to the number of boy games the incidence of injuries is highest in cross-country running and boxing. Stress fractures of the fibula and metatarsals are seen in cross-country running, seldom occurring in other sports. I consider that they are the product of insufficient and too rapid training, the muscular strength increasing disproportionately to that of the bones.

There is very little boxing instruction in the school, but each year an inter-house competition produced a large number of entries and a high proportion of casualties. Fortunately this competition is now in abeyance.

Cricket produces about one-fifth of the casualties compared with rugger, injuries to the teeth, nasal bones and fingers being the commonest. Hockey produces very few casualties.

An attempt has been made to describe the conditions under which the school medical officer works and to mention briefly some of the illnesses and injuries which he encounters. The medical officer working in a public school has some advantages over his colleagues in general practice: the centralization of much of his practice, the control of some environmental factors, the smallness of the number of his patients, and the completeness of information about the patients. There are als@ several hidden advantages in such a life: one is \& member of a pleasant community, with facilities for many forms of sport, good music is readily available, amateur theatricals and other forms of entertainment are to hand, and one has the constant stimulus of being associated with many gifted people with high ideals of service. 